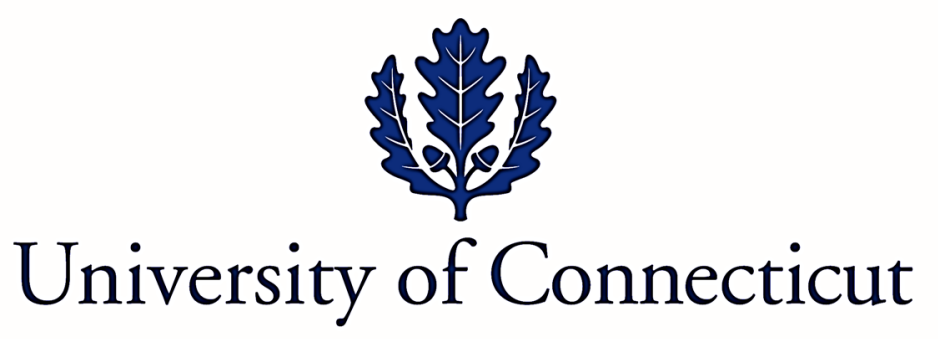

Department of Economics Working Paper Series

\title{
Using Partial Identification Methods to Estimate the Effect of \\ Violence Against Women on Their Children's Health Outcomes
}

by

Jorge M. Agüero

University of Connecticut

Working Paper 2016-23

July 2016

365 Fairfield Way, Unit 1063

Storrs, CT 06269-1063

Phone: (860) 486-3022

Fax: (860) 486-4463

http://www.econ.uconn.edu/

This working paper is indexed in RePEc, http://repec.org 


\title{
Using Partial Identification Methods to Estimate the Effect of Violence Against Women on Their Children's Health Outcomes
}

\author{
Jorge M. Agüero \\ University of Connecticut \\ Department of Economics and El Instituto \\ 365 Fairfield Way, Unit 1063 \\ Storrs, CT 06269-1063, USA \\ Phone: +1860.486 .0263$ \\ Fax: $(+1) 860.486 .4463$ \\ jorge.aguero@uconn.edu
}

July 2016

Running title: Violence Against Women and Child Health Outcomes

\begin{abstract}
Non-experimental studies evaluate the robustness of their treatment effects by exploring the sensitivity of their estimates to the inclusion of additional variables. However, recent papers have shown that such heuristic approaches are insufficient. Instead, partial identification methods have been proposed to bound non-experimental estimates. I use proportional selection relationships to estimate the relative size of the unobservables needed to eliminate the estimated effects. I apply this method to test the effects that violence against women has on the health outcomes of their children, a research area that lacks credible identification strategies. Also, to expand the external validity of my analysis, I use data from five standardized nationally representative household surveys in Latin America. Consistent with previous studies, OLS estimates show large negative associations between violence against women and an array of child health outcomes. However, when accounting for omitted variable bias, at best, two-thirds of the estimates remain robust and they are concentrated on the outcomes with the largest crosssectional estimated impacts.
\end{abstract}

JEL Classifications: I10, I12, J16.

Keywords: Partial identification, domestic violence, children's health, Latin America.

Manuscript word count: 2,063 . 


\section{Introduction}

The World Health Organization asserts that intimate partner violence is a major challenge to global public health (WHO, 2011). In Latin America, violence against women (VAW) is among the most pervasive type of violence (Heinemann and Verner, 2006) and estimates suggest that at least one in five women in the region experience such violence.

A recent World Bank report (Klugman et al, 2014) argues that VAW has serious shortand long-term consequences for survivors and their children. The effects on children go beyond behavioral and emotional problems and include outcomes traditionally related to poverty and deprivation. For example, studies have found that violence against women is associated with reductions in vaccination prevalence, lower birth weight, and with more diarrhea cases and child malnutrition (Holt el at, 2008). These early-childhood indicators are of special interest given the growing literature linking them to negative adult economic outcomes in developed and developing countries (Currie and Vogl, 2013). Thus, understanding the effects of VAW on children's health outcomes is of great interest for economists as well as policy makers. However, unlike other interventions affecting child health outcomes (e.g., cash transfers, deworming), the negative associations from VAW are not causal because the literature lacks credible exogenous sources of variation for this violence.

To circumvent this problem, my paper tests whether such associations are robust to the possibility of omitted variable biases using proportional selection relationship, a partial identification method developed by Altonji et al (2005) and expanded by Oster (2015). To increase the external validity, I use data from five Latin American countries with standardized questions regarding VAW and child health outcomes. Consistent with previous results, OLS estimates show large and significant associations between several measures of violence and children's health outcomes such as prevalence of diarrhea, cough and fever but also on malnutrition. However, I find that only two-thirds of the estimates are robust when possible omitted variable bias is considered, weakening the evidence about these negative impacts.

\section{Data}

I use the Demographic and Health Surveys (DHS) from Colombia (2009-2010), the Dominican Republic (2007, 2013), Haiti (2005-2006, 2012), Honduras (2005-2006) and Peru (2000, 2004- 
2012). DHS are nationally representative cross-sectional surveys collecting information about women between the ages of 15 and 49 and their families. These surveys use a standardized questionnaire (across years and countries) to collect information about violence against women as well as health outcomes for their children under the age of five. This age restriction allows me to focus on outcomes early in life as typically explored in the early childhood literature. The DHS captures measures of violence using the World Health Organization ethical and safety guidelines by privately asking specific question about incidents (e.g., "Did your partner slap you?") in the last 12 months ${ }^{1}$. Incidents are grouped into sexual and physical violence and I also consider the union of all incidents (any violence). Child health outcomes include diarrhea, fever and cough episodes (two weeks prior to the survey), as well as measures of malnutrition such as anemia (from blood samples) and anthropometric (obtained by trained nurses).

\section{Methodology}

The following regression relates the health outcome, $Y_{i j t}$, of child $i$, living in location $j$, observed in year $t$ with whether her mother experienced violence $\left(V_{i j t}\right)$

$$
\mathrm{Y}_{\mathrm{ijt}}=\beta \mathrm{V}_{\mathrm{ijt}}+\pi \mathrm{X}_{\mathrm{ijt}}+\theta \mathrm{Z}_{\mathrm{ijt}}+\mathrm{W}_{\mathrm{ijt}}+\mathrm{e}_{\mathrm{ijt}}
$$

The parameter of interest is $\beta$. Let $X_{i j t}$ be a set of basic controls that are not expected to share covariance properties with the unobservables. In my analysis these variables include child's and mother's age as well as survey year and country fixed-effect. Vector $Z_{i j t}$ contains controls that applied researchers would use to gauge the sensitivity of their $\beta$ estimates. These variables are suspected to be correlated with both the probability of violence and with unobservables affecting child outcomes. In my analysis, I consider variables related to socio-economic status, cultural issues and female empowerment. Thus, in vector $Z_{i j t}$, I include mothers' years of schooling, marital status, location (urban/rural), height, labor force participation status and use of modern contraceptives. If estimates of $\beta$ are not sensitive to the inclusion of $Z_{i j t}$, researchers tend to conclude that their findings are less affected by the omitted variable bias. Yet, in nonexperimental settings, it is difficult to obtain consistent estimates of $\beta$ due to the presence of unobervables as captured by $W_{i j t}$.

\footnotetext{
${ }^{1}$ See Agüero (2013) for more details about these questions and alternative measures for these countries.
} 
The use of the observables $(Z)$ to identify the bias from the unobservables $(W)$ requires further assumptions about the covariance properties of the two sets of variables. Altonji et al (2005), propose the use of a ratio ( $\delta$ ) that measures the influence of the unobservables required to eliminate the treatment effect and set $\beta=0$. Applied to equation (1), $\delta$ is defined by

$$
\delta \frac{\sigma_{Z V}}{\sigma_{Z Z}}=\frac{\sigma_{W V}}{\sigma_{W W}}
$$

where $\sigma_{\mathrm{MV}}=\operatorname{Cov}(M, V), \sigma_{\mathrm{MM}}=\operatorname{Var}(M)$, for $M=\{Z, W\}$. This proportional selection relationship implies that if, for example, $\delta=3$ the role of the unobservables $\left(\sigma_{\mathrm{WV}} / \sigma_{\mathrm{WW}}\right)$ needs to be three times as important as the role of the observables $\left(\sigma_{\mathrm{ZV}} / \sigma_{\mathrm{ZZ}}\right)$ in order to eliminate the treatment effect. The authors consider an upper bound of $\delta=1$, so that a value of $\delta<1$ serves as an indicator of an inconsistent estimate of $\beta$ because it would be enough for the unobservables to play a small role in order to eliminate the effect.

Oster (2015) extends this approach and shows that $\delta$ is not a global measure but rather depends on the R-squared of a hypothetical regression of the outcome $(Y)$ on the treatment $(V)$ as well as $X, Z$ and $W$. She shows that Altonji et al's method assumes the outcome is fully explained by the entire set of variables, leaving no room for disturbances or residual errors. This is clearly an extreme case as the maximum $\mathrm{R}$-squared possible $\left(\mathrm{R}_{\max }\right)$ of this hypothetical regression would be equal to 1 . Oster considers more realistic values $\left(\mathrm{R}_{\max }<1\right)$ so the goal is to, for a given value of $R_{\max }$, estimate the value of $\delta$ that sets $\beta=0$. I apply this partial identification method to evaluate the robustness of the effect of VAW on child health outcomes.

\section{Results}

Table 1 displays the estimates from equation (1) and shows statistically significant associations between violence and child health outcomes, after including the observable controls $(X$ and $Z)$. In all regressions, robust standard errors clustered at the primary sampling unit are used (132 clusters). Consistent with previous studies, I find that Latin American children whose mothers experienced any type of violence in the last 12 months are more likely to have diarrhea (33\%), to be anemic (5\%), and to have fever (18\%) and cough (14\%). Children tend to be shorter $(-3 \%)$ 
and weigh much less $(-13 \%)$ than their counterparts born to women who did not experience violence during the same period. A naïve interpretation of these estimates would suggest large (for most) and negative consequences (for all) of violence on child health outcomes.

How large does the role of the unobservables need to be in order to invalidate this interpretation? In Table 2, I answer this question by estimating the coefficient of proportionality $\delta$, for different levels of $\mathrm{R}_{\max }$ and for each of the regressions displayed before. For the extreme case of $R_{\max }=1$, none of the estimates satisfy Altonji et al's criteria ${ }^{2}$ (column 2). It takes a small role for the unobservables to eliminate the effects given that $\delta<1$ in all regressions. This rejection rate is large compared to Oster's, who finds that $13 \%-20 \%$ of the results from articles using nonrandomized data published in the top-four economic journals survive $\mathrm{R}_{\max }=1$. Following Oster (2015), when considering more realistic values, such as $R_{\max }=\operatorname{Min}\left\{2 R^{2}, 1\right\}$, half of the estimates survive the criteria (column 3) compared to $34 \%$ in top-journals. When considering $\mathrm{R}_{\max }=\operatorname{Min}\left\{1.25 \mathrm{R}^{2}, 1\right\}$, I find that $67 \%$ have $\delta>1$ (column 5 ) compared to Oster's $46-61 \%$ among top-journal articles. Thus, for the case of the effect of violence against women on child health outcomes, the survival rate is closer to the ranges reported in Oster's analysis only when using more plausible values of $\mathrm{R}_{\max }$.

\section{Conclusions}

Estimating the effect of violence against women on child health outcomes has attracted the attention of researchers and policy makers. Recent studies show strong correlations in the case of developing countries (Rawlings and Siddique, 2014), but ignore the possible bias due to omitted variables. Given the lack of credible identification strategies, I extend the literature by using recent methods regarding proportional selection relationship and find that, when considering strict benchmarks, none of the associations between violence and child health outcomes are robust to such biases. However, for more plausible benchmarks, at best, two-thirds of the estimates are robust to omitted variable biases. The estimates for diarrhea and fever are the largest and appear to be the most robust. This suggests weaker evidence about the effect of VAW on child health. Future research should explore whether these findings hold for other child

\footnotetext{
${ }^{2}$ Note that for some regressions, there is even a sign difference between the role of the observables and unobservables as some $\delta$ are negative.
} 
outcomes, in other regions, and how these findings relate to yet-to-occur experimental studies exogenously affecting violence against women in order to measure the health costs of such violence.

\section{References}

Agüero, J. 2013. "Causal Estimates of the Intangible Costs of Violence against Women in Latin America and the Caribbean.” Inter-American Development Bank, Working Paper No. 414.

Altonji, J. G., T. E. Elder, and C. R. Taber. 2005. "Selection on Observed and Unobserved Variables: Assessing the Effectiveness of Catholic Schools," Journal of Political Economy, 113(1), 151-184.

Currie, J. and Vogl, T., 2013. "Early-Life Health and Adult Circumstance in Developing Countries". Annual Review of Economics, 5, pp.1-36.

Heinemann, A. and D. Verner. 2006. "Crime and Violence in Development: A Literature Review of Latin America and the Caribbean." Policy Research Working Paper Series 4041. Washington, DC, United States: World Bank.

Holt, S., Buckley, H. and Whelan, S., 2008. The impact of exposure to domestic violence on children and young people: A review of the literature. Child Abuse \& Neglect, 32(8): 797-810.

Klugman, J., Hanmer, L., Twigg, S., Hasan, T., McCleary-Sills, J. and Santamaria, J., 2014. Voice and agency: Empowering women and girls for shared prosperity. World Bank Publications.

Oster, E. 2015. "Unobservable Selection and Coefficient Stability: Theory and Evidence." Mimeograph, Brown University. NBER WP No. 19054

Rawlings, S. and Z. Siddique. 2014. "Domestic Abuse and Child Health”, IZA DP No. 8566, October.

World Health Organization. 2011. "Violence against Women: Intimate Partner and Sexual Violence against Women." Fact Sheet 239. 
Table 1. Correlates between violence against women and child's health outcomes

\begin{tabular}{|c|c|c|c|c|c|}
\hline $\begin{array}{l}\text { Child's health } \\
\text { outcome }\end{array}$ & $\begin{array}{l}\text { Type of } \\
\text { violence }\end{array}$ & $\begin{array}{c}\text { Observations } \\
(1)\end{array}$ & $\begin{array}{l}\text { Mean of } \\
\text { health } \\
\text { outcome } \\
(2)\end{array}$ & $\begin{array}{c}\text { Coefficient } \\
\text { (3) }\end{array}$ & $\begin{array}{l}\text { Robust and } \\
\text { clustered } \\
\text { standard } \\
\text { errors } \\
\text { (4) }\end{array}$ \\
\hline \multirow[t]{3}{*}{ Diarrhea $(=1)$} & Any & 56335 & 0.172 & $0.056 * * *$ & 0.004 \\
\hline & Physical & 56344 & 0.172 & $0.058 * * *$ & 0.004 \\
\hline & Sexual & 56336 & 0.172 & $0.065 * * *$ & 0.006 \\
\hline \multirow[t]{3}{*}{ Anemic $(=1)$} & Any & 41028 & 0.377 & $0.017 * * *$ & 0.004 \\
\hline & Physical & 41035 & 0.377 & $0.017 * * *$ & 0.004 \\
\hline & Sexual & 41031 & 0.377 & 0.005 & 0.008 \\
\hline \multirow{3}{*}{$\begin{array}{l}\text { Weight-for-age } \\
\text { (z-score) }\end{array}$} & Any & 54193 & 0.174 & $-0.022 * *$ & 0.010 \\
\hline & Physical & 54202 & 0.174 & $-0.021 * *$ & 0.010 \\
\hline & Sexual & 54196 & 0.174 & $-0.033 * *$ & 0.016 \\
\hline \multirow{3}{*}{$\begin{array}{l}\text { Height-for-age } \\
\text { (z-score) }\end{array}$} & Any & 54189 & -0.934 & $-0.027 * * *$ & 0.009 \\
\hline & Physical & 54198 & -0.934 & $-0.028 * * *$ & 0.010 \\
\hline & Sexual & 54192 & -0.934 & $-0.035 * *$ & 0.017 \\
\hline \multirow[t]{3}{*}{ Fever $(=1)$} & Any & 56334 & 0.256 & $0.046^{* * *}$ & 0.004 \\
\hline & Physical & 56343 & 0.256 & $0.047 * * *$ & 0.004 \\
\hline & Sexual & 56335 & 0.256 & $0.060 * * *$ & 0.008 \\
\hline \multirow[t]{3}{*}{ Cough $(=1)$} & Any & 56338 & 0.394 & $0.055 * * *$ & 0.005 \\
\hline & Physical & 56347 & 0.394 & $0.056^{* * *}$ & 0.005 \\
\hline & Sexual & 56339 & 0.394 & $0.071 * * *$ & 0.007 \\
\hline
\end{tabular}

Note: Each row represents a separate regression. See text for details. Significance at 1\%, 5\% and $10 \%$ are indicated by $* * *, * *$ and $*$, respectively. 
Table 2. Sensitivity analysis

\begin{tabular}{|c|c|c|c|c|c|c|}
\hline \multirow{2}{*}{$\begin{array}{l}\text { Child's health } \\
\text { outcome }\end{array}$} & \multirow{2}{*}{$\begin{array}{l}\text { Type of } \\
\text { violence }\end{array}$} & \multirow[b]{2}{*}{$\begin{array}{l}\mathrm{R}^{2} \\
(1)\end{array}$} & \multicolumn{4}{|c|}{$\delta$ with $R_{\max }$ equal to } \\
\hline & & & $\begin{array}{l}1.0 \\
(2)\end{array}$ & $\begin{array}{c}\operatorname{Min}\left\{2 \mathrm{R}^{2}, 1\right\} \\
(3)\end{array}$ & $\operatorname{Min}\left\{1.5 \mathrm{R}^{2}, 1\right\}$ & $\operatorname{Min}\left\{1.25 \mathrm{R}^{2}, 1\right\}$ \\
\hline \multirow[t]{3}{*}{ Diarrhea } & Any & 0.069 & 0.296 & 3.802 & 7.186 & 12.95 \\
\hline & Physical & 0.069 & 0.254 & 3.235 & 6.092 & 10.91 \\
\hline & Sexual & 0.066 & 0.129 & 1.774 & 3.455 & 6.563 \\
\hline \multirow[t]{3}{*}{ Anemic } & Any & 0.209 & -21.54 & -81.56 & -162.9 & -325.0 \\
\hline & Physical & 0.209 & 0.223 & 0.843 & 1.685 & 3.362 \\
\hline & Sexual & 0.209 & 0.009 & 0.034 & 0.068 & 0.136 \\
\hline \multirow[t]{3}{*}{ Weight-for-age } & Any & 0.161 & -0.147 & -0.764 & -1.527 & -3.050 \\
\hline & Physical & 0.161 & -0.367 & -1.911 & -3.820 & -7.633 \\
\hline & Sexual & 0.161 & 0.053 & 0.274 & 0.548 & 1.095 \\
\hline \multirow[t]{3}{*}{ Height-for-age } & Any & 0.315 & 0.532 & 1.159 & 2.318 & 4.633 \\
\hline & Physical & 0.315 & 0.616 & 1.341 & 2.682 & 5.360 \\
\hline & Sexual & 0.314 & 0.145 & 0.317 & 0.633 & 1.266 \\
\hline \multirow[t]{3}{*}{ Fever } & Any & 0.035 & 0.374 & 9.631 & 18.23 & 32.91 \\
\hline & Physical & 0.036 & 0.272 & 6.956 & 13.12 & 23.57 \\
\hline & Sexual & 0.035 & 0.115 & 3.105 & 6.008 & 11.28 \\
\hline \multirow[t]{3}{*}{ Cough } & Any & 0.052 & -0.446 & -7.833 & -14.98 & -27.57 \\
\hline & Physical & 0.052 & -1.126 & -19.69 & -37.59 & -68.92 \\
\hline & Sexual & 0.051 & 0.243 & 4.452 & 8.677 & 16.51 \\
\hline
\end{tabular}

Notes: Columns (2)-(5) show the value of $\delta$ needed to set $\beta=0$ for a given value of $R_{\max }$. See text for details. 